\title{
Multiple therapeutic peptide vaccines for patients with advanced gastric cancer
}

\author{
YOSHIYUKI FUJIWARA ${ }^{1,2}$, KAORU OKADA ${ }^{2}$, TAKESHI OMORI ${ }^{2}$, KEIJIRO SUGIMURA $^{2}$, \\ HIROSHI MIYATA ${ }^{2}$, MASAYUKI OHUE ${ }^{2}$, SHOGO KOBAYASHI ${ }^{2}$, HIDENORI TAKAHASHI ${ }^{2}$, \\ HIROYUKI NAKANO ${ }^{3}$, CHIE MOCHIZUKI $^{3}$, KATSUJI SHIMIZU ${ }^{3}$, MASAHIKO YANO $^{2}$, \\ YUSUKE NAKAMURA ${ }^{4}$, MASAKI MORI $^{5}$ and YUICHIRO DOKI ${ }^{5}$
}

\author{
${ }^{1}$ Department of Surgery, Division of Surgical Oncology, Faculty of Medicine, Tottori University, Yonago 683-8504; \\ Departments of ${ }^{2}$ Surgery and ${ }^{3}$ Pharmacy, Osaka Medical Center for Cancer and Cardiovascular Diseases, \\ Osaka 537-8511, Japan; ${ }^{4}$ Center for Personalized Therapeutics, The University of Chicago, Chicago, IL 60637, USA; \\ ${ }^{5}$ Department of Gastroenterological Surgery, Graduate School of Medicine, Osaka University, Osaka 565-0871, Japan
}

Received January 24, 2017; Accepted March 29, 2017

DOI: 10.3892/ijo.2017.3955

\begin{abstract}
We performed a clinical trial using HLA-A24binding peptide vaccines containing a combination of novel cancer-testis antigens and anti-angiogenic peptides for advanced gastric cancer (GC). Thirty-five GC patients who had shown resistance to the standard therapy were enrolled in this clinical trial using vaccinations with a mixture of multiple peptides derived from DEPDC1, URLC10, FoxM1, Kif20A and VEGFR1. The safety, the overall survival (OS), and the immunological responses based on an ELISPOT assay were determined to assess differences in patients who were HLA-A24-positive [24(+)] and HLA-A24-negative [24(-)]. No severe adverse effects were observed except for severe skin reactions in 4 patients. The differences in OS were not significant between patients who were 24(+) and 24(-). In the 24(+) group, patients who showed T cell responses specific to antigen peptides had a tendency towards better survival than those who showed no response, especially to the DEPDC1 peptide. The patients with local skin reactions had significantly better OS than the others. Peptide vaccine therapy was found to be safe and is expected to induce specific $\mathrm{T}$ cell responses in patients with advanced GC. The survival benefit of peptide vaccine monotherapy may not have been shown and further trials are needed to confirm these results.
\end{abstract}

Correspondence to: Professor Yoshiyuki Fujiwara, Department of Surgery, Division of Surgical Oncology, Faculty of Medicine, Tottori University, 36-1 Nishicho, Yonago 683-8504, Japan

E-mail: y-fujiwara@med.tottori-u.ac.jp

Key words: gastric cancer, peptide vaccine, immunotherapy, URLC10, DEPDC1, FoxM1, KIF20A, VEGFR-1

\section{Introduction}

Although the incidence of gastric cancer (GC) has been declining worldwide over the past few decades, the reported frequency of GC-related mortality in 2008 was still the fourth highest in males and fifth highest in females (1). In Japan, GC is one of the most common causes of death, despite advances in diagnosis and treatment. Particularly, unresectable or recurrent GC is associated with an extremely poor prognosis even when treated with novel therapeutic agents, including taxanes (paclitaxel and docetaxel), irinotecan, S-1, oxaliplatin and capecitabine, which are known to be efficacious in gastric cancer (2-7). A multi-center randomized controlled trial (SPIRITS trial) performed in Japan reported that the median overall survival and progression-free survival in patients with advanced GC treated with S-1 plus cisplatin were significantly longer in those treated with S-1 alone (8). Therefore, the Gastric Cancer Treatment Guidelines 2010 issued by the Japanese Gastric Cancer Association recommended the S-1 plus cisplatin combination regimen as the standard first-line treatment for unresectable and recurrent GC (9). However, even with this treatment, the median overall survival was 13 months, and the progression-free survival time was 6 months, suggesting the need for novel therapeutic modalities. Recently, novel molecular targeted therapies, such as trastuzumab and ramucirumab, have shown additional therapeutic effects $(10,11)$; however, their survival benefits are limited.

After identification of tumor associated antigens, such as the MAGE family in 1991, cancer immunotherapy has become a promising approach to fight cancer with minimum toxicity $(12,13)$. Recently, several clinical trials using peptide vaccine therapy targeting cancer-specific antigen peptides have been performed in the world and suggested improvement in patient survival (14-16).

We identified novel cancer-testis antigens that showed specific overexpression in GC tissues using the genomewide cDNA microarray method. Forkhead box protein M1 
(FoxM1) is a member of the Forkhead family of transcription factors $(17,18)$. FoxM1 plays important roles in the cell cycle by regulating both the transition from the G1 to $\mathrm{S}$ phase and progression to mitosis (18-20). Recently, FoxM1 has been linked to tumorigenesis and progression of several types of malignancies. Overexpression of FoxM1 has been observed in various cancers of the liver, breast, prostate, brain, cervix, colon and lung (21-27). We also showed that FoxM1 was overexpressed in GC and its overexpression was a significant prognostic factor and had an association with chemo-resistance in GC (28). Upregulated lung cancer 10 (URLC10), KIF20 and DEPDC1, which have been used for cancer vaccine therapy as oncogenic peptides (29-31), were also confirmed to show overexpression in GC. A vaccination with a peptide derived from vascular endothelial growth factor receptor-1 (VEGFR-1) has also been reported to show cytotoxicity for tumors as an antiangiogenic cancer vaccine (32).

In the present study, multiple therapeutic peptide vaccines consisting of 4 cancer-testis antigens (FoxM1, URLC10, KIF20 and DEPDC1) and one anti-angiogenic peptide, i.e., VEGFR1, were administered to unresectable and recurrent GC patients who showed resistance to the standard chemotherapy and their efficacy and safety were assessed.

\section{Materials and methods}

Patient eligibility. Patients diagnosed with gastric adenocarcinoma that was considered unresectable or who had recurrent disease and failed to respond to the standard therapy were enrolled in this trial at the Department of Gastroenterological Surgery, Osaka University Hospital or the Department of Surgery, Osaka Medical Center for Cancer and Cardiovascular Diseases. The following were the other main inclusion criteria: i) Eastern Cooperative Oncology (ECOG) performance status of 0 or 1; ii) age between 20 years and 84 years; iii) adequate bone-marrow, cardiac, pulmonary, hepatic and renal functions including leukocyte count $2,000-10,000 / \mathrm{mm}^{3}$, platelet count $>70,000 / \mathrm{mm}^{3}$, hemoglobin level $>8.0 \mathrm{~g} / \mathrm{dl}$, aspartate aminotransferase and alanine aminotransferase $<100 \mathrm{U} / 1$, total bilirubin $<1.5$, and creatinine $<1.5$ times the institutional normal upper limits; iv) life expectancy $>3$ months; v) no therapy in 4 weeks prior to the initiation of this study; and vi) signed informed consent. The main exclusion criteria were: i) the presence of another serious disease such as uncontrolled diabetes, hepatic disorder, cardiac disease, or hemorrhage/ bleeding; ii) pregnant or breast-feeding woman; iii) patients who planned to become pregnant during the study period; iv) symptomatic infectious disease; v) need for concurrent treatment with steroids or immunosuppressive agents; vi) uncontrolled other malignant disease; vii) unhealed wound; viii) intestinal obstruction or interstitial pneumonia; and ix) decision of unsuitableness by the principal investigator or physician in charge.

Study design. The present study was a phase II open-label, non-randomized cancer vaccine trial for unresectable or recurrent $\mathrm{GC}$ in patients who had failed to respond to the standard therapy in an exploratory setting. All enrolled patients received the vaccination without study personnel knowing the patient's HLA-A status and the HLA-A genotypes were key- opened at the analysis point. The HLA genotype information was held by an evaluation committee, and both patients and investigators were blinded to the results until completion of the study. The HLA-A*2402 restricted epitope peptide cocktail containing peptides for FoxM1, URLC10, KIF20, DEPDC1 and VFGFR1 each at a dose of $1 \mathrm{mg}$ were prepared in incomplete Freund's adjuvant (Montanide ISA-51VG; Seppic, Paris, France) and injected subcutaneously weekly in the inguinal region of the patients. One treatment cycle consisted of four injections on days $1,8,15$ and 22 . The primary endpoints were the safety of the peptide vaccination and overall survival. The secondary endpoints were clinical responses and immunological responses. Toxicities were assessed by the Common Terminology Criteria for Adverse Events version 4.0 (CTCAE ver4.0). To assess the clinical responses, computed tomography imaging was performed within a month before starting the first cycle and within 2 weeks after every two cycles. Every measurable region such as liver, lung or lymph node metastasis was evaluated by the Response Evaluation Criteria in Solid Tumors (RECIST) (33). The overall survival, which was measured in days from the first vaccination to death, was analyzed by the Kaplan-Meier method. Immunological monitoring was performed with an enzyme-linked immunospot (ELISPOT) assay using in vitro culturing of lymphocytes derived from peripheral blood at pre- and post-vaccination periods as described below.

This trial was approved by the Ethics Committees of both the Osaka University and Osaka Medical Center for Cancer and Cardiovascular Diseases, registered at UMIN (http:// www.umin.ac.jp; Trial registration ID: UMIN000004389), and carried out in accordance with the Helsinki declaration on experimentation on human subjects.

Peptides. HLA-A*2402-restricted CMV peptide (QYDPVAALF), FOXM1-262 (IYTWIEDHF), URLC10-177 (RYCNLEGPPI) (34), DEPDC1-294 (EYYELFVNI) (35), KIF20A-66 (KVYLRVRPLL) (36) and GMP-graded VEGFR1-1084 peptide (SYGVLLWEIF) (32) were synthesized by the American Peptide Co. (Sunnyvale, CA, USA) per a standard solid-phase synthesis method and purified by reversed-phase high-performance liquid chromatography (HPLC). The purity (>90\%) and identity of the peptides were determined by analytical HPLC and mass spectrometry, respectively.

Treatment protocol. A mixture of $1 \mathrm{mg}$ each of FOXM1-262, URLC10-177, DEPDC1-294, KIF20A-66 and VEGFR1-1084 were emulsified together with $1 \mathrm{ml}$ of incomplete Freund's adjuvant and injected subcutaneously at inguinal regions from side to side every week 4 times in one cycle. Toxicities, clinical responses and peptide-specific immunological responses within 2 cycles were evaluated.

Isolation and stock of peripheral blood mononuclear cells. Peripheral blood cells were obtained from patients at the end of every cycle of the treatment. Peripheral blood mononuclear cells (PBMCs) were isolated immediately with a Ficoll-Paque Plus density gradient solution (GE Healthcare, Little Chalfont, UK), suspended in Cell Banker (Juji Field, Inc., Tokyo, Japan) and frozen and stored in liquid nitrogen. 
Enzyme-linked immunospot (ELISPOT) assay. To assess the specific CTL response, an ELISPOT assay was performed following in vitro expansion. Frozen PBMCs derived from the same patient were thawed at the same time, and their viability was confirmed to be $>90 \%$. PBMCs $\left(5 \times 10^{5} / \mathrm{ml}\right)$ were cultured with $10 \mu \mathrm{g} / \mathrm{ml}$ of the respective peptide and $100 \mathrm{IU} / \mathrm{ml}$ of IL-2 (Novartis, Emeryville, CA, USA) at $37^{\circ} \mathrm{C}$. The peptide was added to the culture at day 0 and day 7 (final concentration $10 \mu \mathrm{g} / \mathrm{ml}$ ) and cells were harvested after two weeks. Following $\mathrm{CD}^{+}$cell depletion with a Dynal CD4-positive isolation kit (Invitrogen, Carlsbad, CA, USA) the cells were used as responder cells in the ELISPOT assay. The IFN- $\gamma$ ELISPOT assay was performed using a Human IFN- $\gamma$ ELISPOT PLUS kit (Mabtech, Inc., Cincinnati, OH, USA) per the instructions supplied by the manufacturer. Briefly, HLA-A*2402-positive B-lymphoblast TISI cells (IHWG Cell and Gene Bank, Seattle, WA, USA) were incubated with $20 \mu \mathrm{g} / \mathrm{ml}$ of FOXM1-262, URLC10-177, DEPDC1-294, KIF20A-66 or VEGFR1-1084 peptides overnight, and then the residual peptide in the media was washed out to prepare peptide-pulsed TISI cells as the stimulator cells. Prepared CD4-cells were cultured with peptide-pulsed TISI cells $\left(2 \times 10^{4}\right.$ cells/well) at $1 / 1,1 / 2$, $1 / 4$ and $1 / 8$ mixture ratios of responder cells and stimulator cells (R/S ratio) on 96-well plates (Millipore, Bedford, MA, USA) at $37^{\circ} \mathrm{C}$ overnight. Non-peptide-pulsed TISI cells were used as negative control stimulator cells. All ELISPOT assays were performed in triplicate. The plates were analyzed with an automated ELISPOT reader, ImmunoSPOT S4 (Cellular Technology, Ltd., Cleveland, OH, USA) and ImmunoSpot Professional Software version 5.0 (Cellular Technology). The number of peptide-specific spots was calculated by subtracting the spot number in the control well from the spot numbers in wells with peptide-pulsed TISI cells. The CTL response was considered positive when the average of the peptide-specific spot numbers of three wells was $>15 /$ well and a significant difference $(\mathrm{P}<0.05)$ was demonstrated between the average spot numbers. The sensitivity of our ELISPOT assay was periodically estimated as approximately average by the ELISPOT panel of the Cancer Immunotherapy Consortium (CIC).

Statistical analysis. Statistical analysis was performed using Student's t-test and Fisher's exact test. Overall survival (OS) curves were estimated using the Kaplan-Meier methodology and compared by the log-rank test. $\mathrm{P}<0.05$ were considered significant. All statistical analyses were performed with JMP 8.0.2 software (SAS Institute Inc., Cary, NC, USA).

\section{Results}

Patient characteristics. Thirty-five patients were enrolled in this trial between November 2010 and March 2012. The study database was locked on March 31, 2013 and the genotype of HLA-A was key-opened. Table I shows the patient characteristics at study entry. They included 21 males and 14 females. Six patients had unresectable gastric cancer and the remaining 29 had recurrent disease after surgery. Twenty-four (68.6\%) had HLA-A*2402 [24(+)] and the remaining 11 (31.4\%) were negative for HLA-A*2402 [24(-)]. The patients received at least one vaccination injection (average 13.3 times, from 2 to 48). The backgrounds of the patients were not significantly different
Table I. Patient characteristics.

\begin{tabular}{lccc}
\hline & $\begin{array}{c}\text { Total } \\
(\mathrm{n}=35)\end{array}$ & $\begin{array}{c}\text { With } \\
(\mathrm{n}=2402\end{array}$ & $\begin{array}{c}\text { Without } \\
\text { A2402 } \\
(\mathrm{n}=11)\end{array}$ \\
\hline Age (years) & $64(35-81)$ & $64(34-81)$ & $65(37-76)$ \\
Gender (male/female) & $21 / 14$ & $14 / 10$ & $7 / 4$ \\
Performance status (0/1) & $0 / 35$ & $0 / 24$ & $0 / 11$ \\
Pre-treatment & & & \\
Surgery (+/-) & $29 / 6$ & $20 / 4$ & $9 / 2$ \\
S-1 (+/-) & $30 / 5$ & $22 / 2$ & $8 / 3$ \\
Cisplatin (+/-) & $23 / 12$ & $16 / 8$ & $7 / 4$ \\
CPT-11 (+/-) & $28 / 7$ & $19 / 5$ & $9 / 2$ \\
Taxanes (+/-) & $27 / 8$ & $20 / 4$ & $7 / 4$ \\
Others (+/-) & $10 / 25$ & $8 / 16$ & $2 / 9$ \\
\hline
\end{tabular}

Table II. Toxicity profile.

\begin{tabular}{|c|c|c|c|c|c|c|c|c|}
\hline & \multicolumn{4}{|c|}{$\begin{array}{l}\text { With A2402 } \\
\qquad \begin{array}{c}(n=24) \\
\text { Grade }\end{array}\end{array}$} & \multicolumn{4}{|c|}{$\begin{array}{l}\text { Without A2402 } \\
\qquad \begin{array}{c}(\mathrm{n}=11) \\
\text { Grade }\end{array}\end{array}$} \\
\hline & 1 & 2 & 3 & 4 & 1 & 2 & 3 & 4 \\
\hline Injection-site reaction & 12 & 0 & 4 & l & 4 & 0 & 0 & \\
\hline Leukopenia & 0 & 0 & 0 & 0 & 0 & 0 & 0 & \\
\hline Anemia & 0 & 0 & 0 & 0 & 0 & 0 & 0 & \\
\hline Thrombocytopenia & 0 & 0 & 0 & 0 & 0 & 0 & 0 & \\
\hline Anorexia & 1 & 0 & 0 & 0 & 2 & 0 & 0 & \\
\hline Increase in AST/ALT & 0 & 1 & 1 & 0 & 0 & 0 & 1 & \\
\hline Increase in creatine & 0 & 1 & 1 & 0 & 0 & 0 & 0 & \\
\hline Fever & 0 & 1 & 0 & 0 & 0 & 1 & 0 & \\
\hline Flu-like symptoms & 1 & 0 & 0 & 0 & 0 & 0 & 0 & \\
\hline
\end{tabular}

between 24(+) and 24(-) including age, gender, performance status and prior therapy, as shown in Table I.

Toxicity. Table II lists the adverse effects recorded during the vaccination therapy. The therapy was well-tolerated without any severe adverse events associated with the therapy except for 4 patients in the 24(+) group who showed grade 3 injectionsite reactions. Representative injection-site reactions are shown in Fig. 1. The grade 2 skin reaction is shown in Fig. 1A and the grade 3 skin ulceration is shown in Fig. 1B. One patient suffered grade 4 anemia due to bleeding of a progressive gastric tumor. Grade 3 AST/ALT elevation was observed in 2 patients, and grade 3 creatinine elevation was found in one patient, which could have been caused by disease progression.

Clinical responses. Of 35 patients, 22 cases continued more than 2 cycles ( 8 weeks) and had the computed tomography (CT) scan for evaluation of disease status after induction of vaccination therapy. The clinical responses were classified as partial response (PR) in 0 patients $(0 \%)$, stable disease 
A

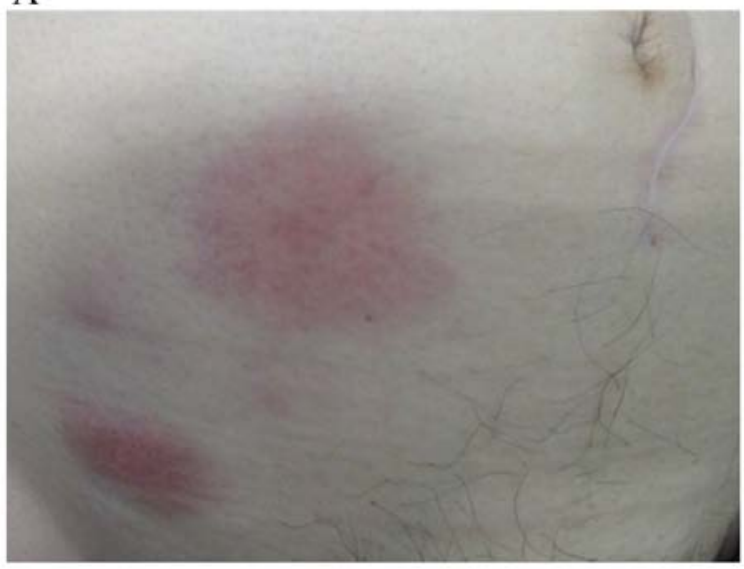

B

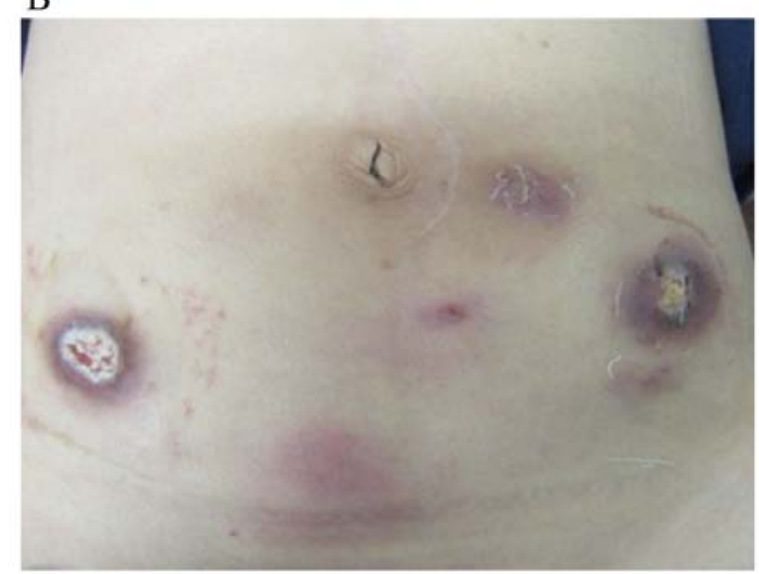

Figure 1. Representative injection-site reactions. (A) Grade 2 skin redness was observed. (B) Grade 3 skin ulceration was observed.

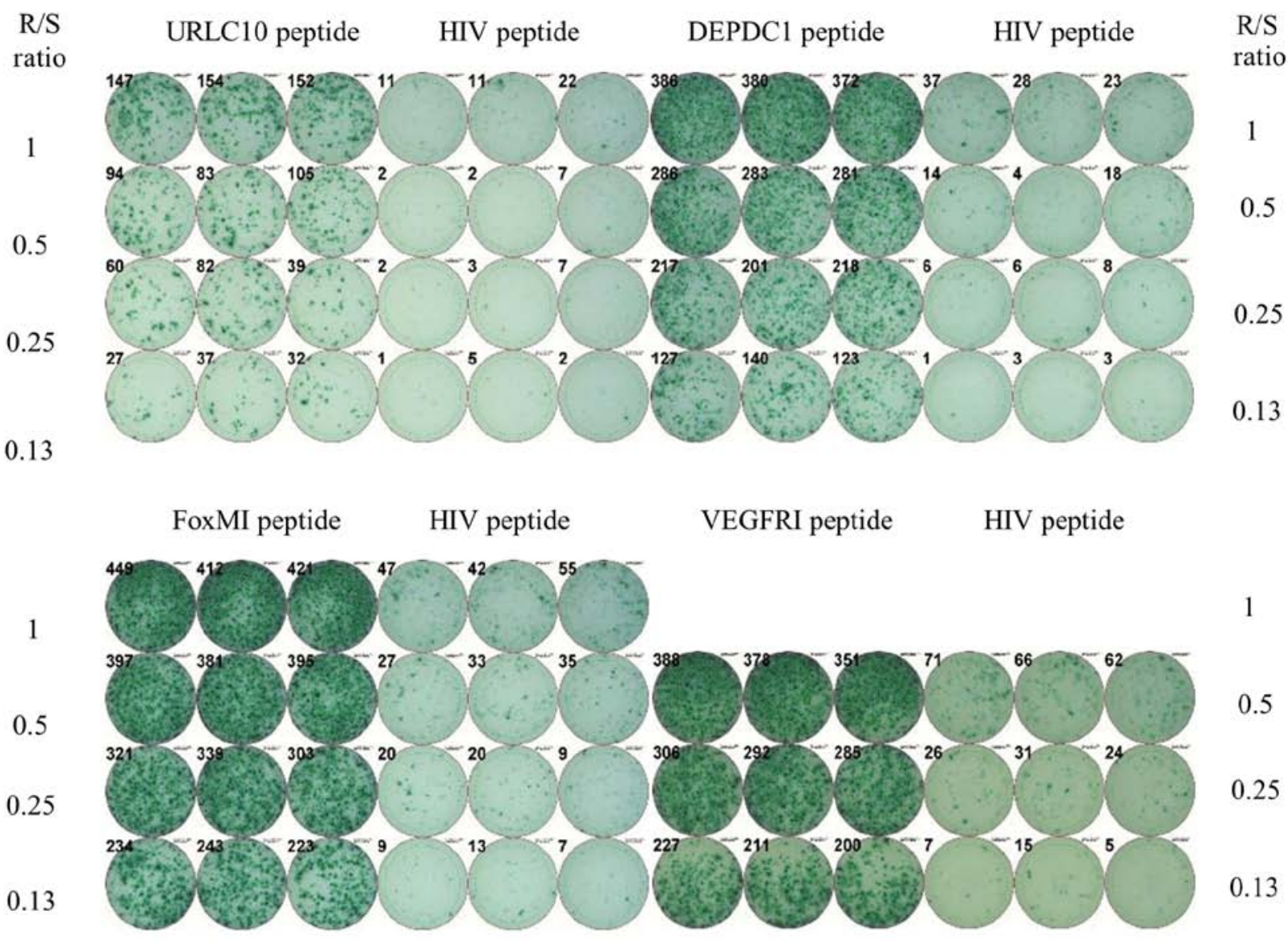

Figure 2. Representative immunological monitoring assays detecting antigen-specific responses. The cultured lymphocytes from patient \#24 were subjected to an ELISPOT assay, which indicated substantial T cell responses specific to the URLC10, DEPDC1, FoxM1 and VEGFR1 peptides in comparison to the control HIV peptide. The spot counts were quantified and shown at the upper-left corner of each well. Peptide-specific immunological reactions were detected for all four peptides in this patient. R/S ratio, responder/stimulator ratio.

(SD) in 10 patients $(45 \%)$ and progressive disease (PD) in 12 patients $(55 \%)$. The remaining 13 patients did not have a posttherapeutic CT scan because the study was stopped within 2 cycles due to disease progression (Table III).

Immunological monitoring. Twenty patients with A24(+) received at least one course of the vaccination and were subjected to immunological analysis with peripheral blood. A representative ELISPOT assay is shown in Fig. 2. Patient 24 showed substantial $\mathrm{T}$ cell responses specific to the URLC10, DEPDC1, FoxM1 and VEGFR1 peptides in comparison to the irrelevant peptide. The positive CTL responses specific for URLC10, DEPDC1, KIF20A, FOXM1 and VEGFR1 were observed in $90,60,60,100$ and $55 \%$ of the patients, respec- 

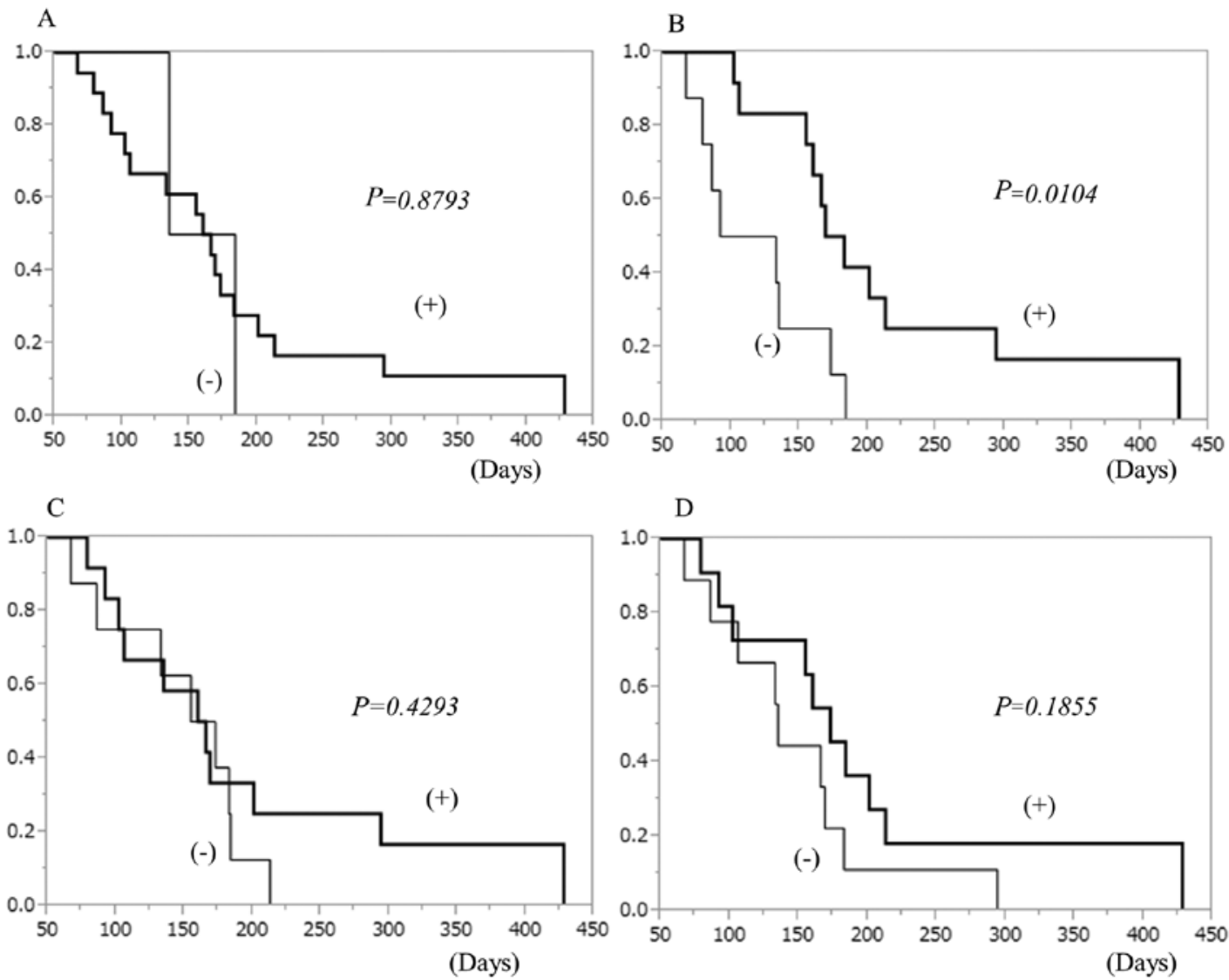

Figure 3. The overall survival (OS) in the A24(+) group per the status of T cell responses specific to the antigen peptide. (A) OS of CTL response to URLC10; (B) OS of CTL response to DEPDC1; (C) OS of CTL response to KIF20A; (D) OS of CTL response to VEGFR1; (+), presence of CTL response; (-), absence of CTL response.

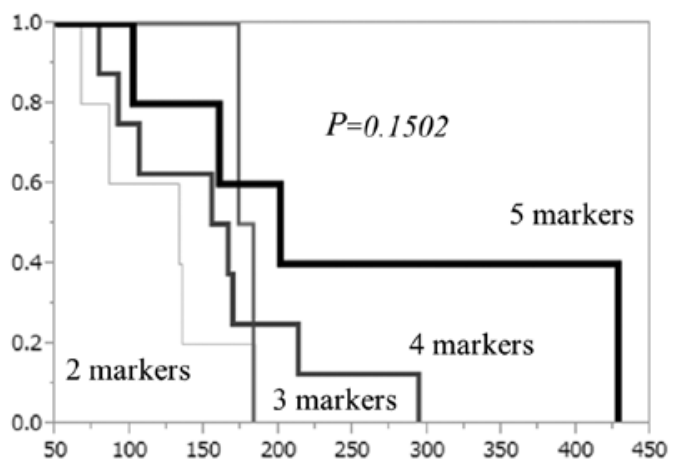

Figure 4. The OS per the number of markers which showed the CTL responses.

tively. All patients showed CTL response specific to multiple antigen peptides (more than one).

Survival analysis. Patients who showed CTL response had a tendency toward better survival than those who showed no response, especially to the DEPDC1 peptide (Fig. 3). The overall survival tended to be better when the number of the peptides that induced CTL responses was higher (Fig. 4). The overall survival curve of all patients is shown in Fig. 5A. The median survival time was 155 days. The association between clinical effects classified by RECIST criteria and survival
Table III. Clinical and immunological outcomes.

\begin{tabular}{lcc}
\hline Factors & Responses & No. of patients $(\%)$ \\
\hline Objective response & SD/PD/NE & $10 / 12 / 13$ \\
Local skin reaction & $+/-$ & $18 / 17$ \\
CTL response (n=20) & & \\
URLC10 & $+/-$ & $18(90 \%) / 2$ \\
DEPDC1 & $+/-$ & $12(60 \%) / 8$ \\
KIF20A & $+/-$ & $12(60 \%) / 8$ \\
FOXM1 & $+/-$ & $20(100 \%) / 0$ \\
VEGFR1 & $+/-$ & $11(55 \%) / 9$ \\
\hline
\end{tabular}

$\mathrm{SD}$, stable disease; $\mathrm{PD}$, progressive disease; $\mathrm{NE}$, not evaluated. +, positive; -, negative.

duration are shown in Fig. 5B. Patients whose tumors showed stable disease after 2 cycles of vaccine therapy had significantly better prognosis than other patients. The survival curves depending on HLA-A type are shown in Fig. 5C. There was no significant difference between patients with HLA-A2402 and those with other types. Local skin reactions were observed in 18 patients (Table III). Patients who suffered local skin reactions due to vaccine injections showed significantly better prognosis than those without skin reactions (Fig. 5D). 

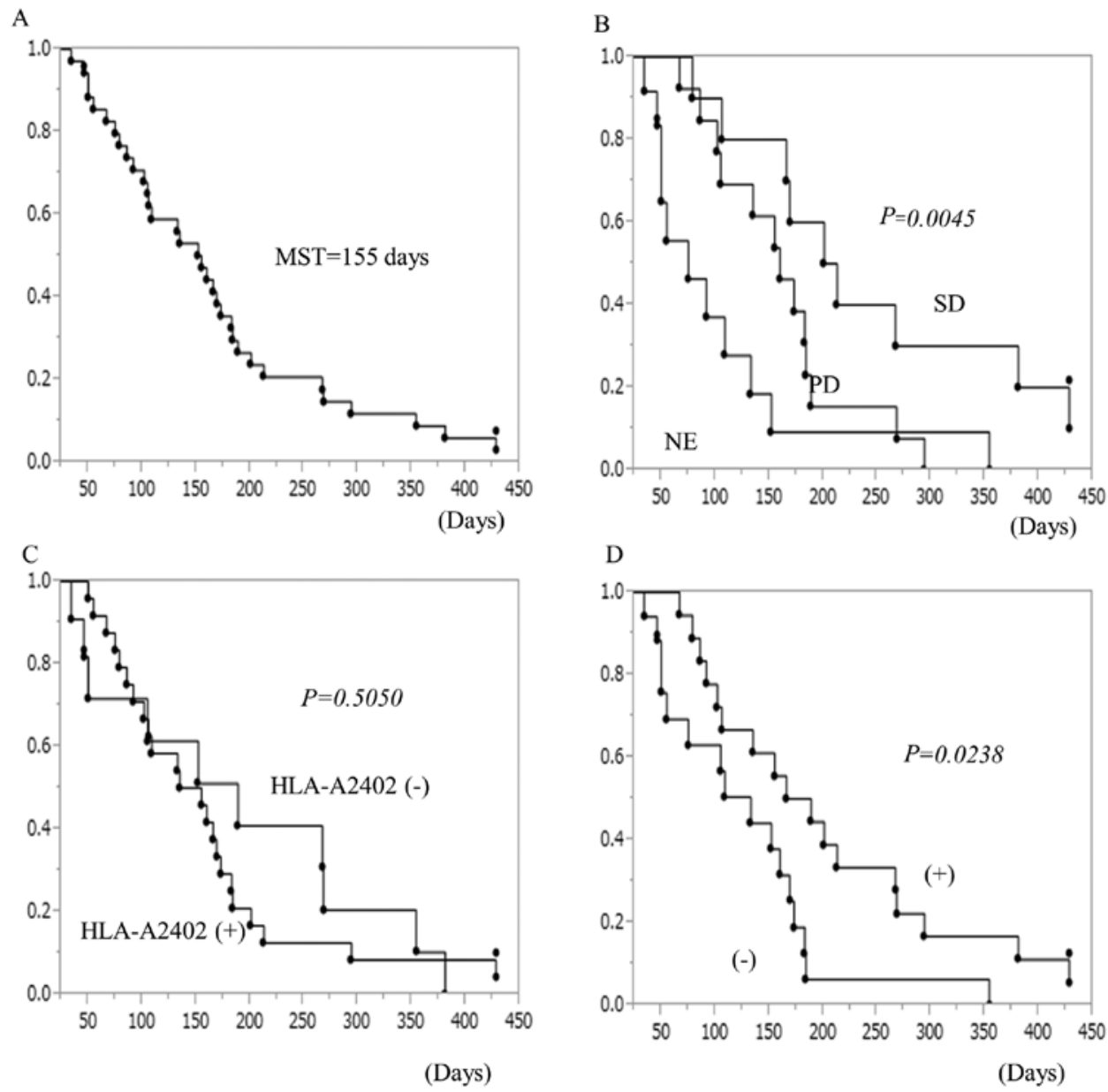

Figure 5. The OS for all enrolled patients. (A) OS in all enrolled patients. MST, median survival time. (B) OS depending on clinical responses after 2 cycles of vaccine therapy; SD, stable disease; PD, progressive disease; NE, not evaluated. (C) OS depending on HLA-A status. (D) OS depending on the presence or absence of local skin reaction; (+), presence of skin reaction; (-), absence of skin reaction

\section{Discussion}

In the present study, we developed a cancer vaccine therapy with multiple peptides specific for GC and we applied it in advanced GC patients who had failed to respond to the standard therapy as a monotherapy. Thirty-five patients were enrolled in this trial; 24 (69\%) patients had HLA-A2402, and the remaining 11 did not have it, which was information that was key-opened at the end of the present study. The differences between the cases with HLA-A2402 and those without were not significant in this study, which might indicate that cancer vaccine treatment with multiple peptide antigens did not provide clinical benefit to advanced GC patients. However, in the A24(+) group, the patients that had a CTL response to a specific peptide, especially DEPDC1, had a better prognosis. Furthermore, patients that had a local skin reaction had a significantly better prognosis than those without local skin reactions. These results might indicate an association between the vaccination-induced immune response and patient prognosis.

According to the present study, the cancer vaccination using a combination of multiple peptides (DEPDC1, FoxM1, KIF20, URLC10 and VEGFR1) were well tolerated by advanced GC patients who had failed to respond to standard therapy. Furthermore, specific cytotoxic $\mathrm{T}$ cells for these five peptide antigens were frequently observed in the peripheral blood of patients after vaccinations, and patients who showed the CTL induction tended to have a better prognosis than those with no CTL induction. First, we chose four cancer antigens suitable for $\mathrm{GC}$ because of the following preferable characteristics: frequent and homogeneous expression in tumor tissues, cancer-specific expression and high immunogenicity. FoxM1 is a well-studied molecule associated with cancer development, and we have reported that its overexpression makes it worth consideration as a prognostic marker in GC (28). DEPDC1, KIF20 and URLC10 were also reported as cancerspecific antigens and have been applied in peptide vaccination therapy (29-31,34-36). An anti-angiogenic vaccine targeting VEGFR-1 was also widely studied in patients with advanced solid tumors $(29,32)$. Previously, we performed a phase II clinical trial with the combination therapy of chemotherapy and peptide vaccine therapy using VEGFR-1 and VEGFR-2 (37). In this trial, the combination therapy was well tolerated and high frequent CTL induction specific for anti-angiogenic peptides was observed despite the combined chemotherapy.

Kono et al (38) performed a clinical study of cancer vaccine treatment with HLA-A24-restricted multi-epitope peptides (TTK, LY6K and IMP3) as monotherapy for 60 advanced 
esophageal cancer patients. They showed that, although the overall survival between A24(+) and A24(-) groups was not significantly different, the progression-free survival in the A24(+) group was significantly better than that in the A24(-) group. In the A24(+) group, the specific CTL response to multiple peptides could improve overall survival of esophageal cancer patients. They concluded that cancer vaccine treatment with multiple peptides as a monotherapy can be a promising therapy for patients with advanced esophageal cancer who had failed to respond to standard therapy. Although we used a HLA-A24-restricted peptide vaccine, the survival benefit in A24(+) patients was not observed in the present study. We speculated that this was due to the number of enrolled patients, 35 was small and only $22(63 \%)$ of the enrolled patients continued until at least two cycles ( 8 times) of vaccines were complete. The remaining 13 patients discontinued vaccines due to disease progression because we enrolled patients with far-advanced diseases, who showed resistance to multiple regimens of chemotherapy. The US FDA published guidance for therapeutic cancer vaccines (39) that indicated that the appearance of a clinical effect in cancer vaccine therapy may be delayed compared to chemotherapy due to the mechanism of immune responses, and longer observation periods may be needed to evaluate the clinical effects. It is hard to expect clinical benefits for patients after multiple chemotherapy regimens due to very poor immune system status. They recommended that cancer vaccine treatment was more suitable for cancer patients as an adjuvant therapy after curative surgery.

In conclusion, peptide vaccine therapy using a mixture of five peptides was found to be safe and could induce specific $\mathrm{T}$ cell responses in patients with advanced GC. The survival benefit of peptide vaccine monotherapy may not have been shown for patients with far advanced GC in this preliminary study, and further studies are needed to confirm these results.

\section{References}

1. Torre LA, Bray F, Siegel RL, Ferlay J, Lortet-Tieulent J and Jemal A: Global cancer statistics, 2012. CA Cancer J Clin 65 : 87-108, 2015.

2. Ajani JA, Fairweather J, Dumas P, Patt YZ, Pazdur R and Mansfield PF: Phase II study of Taxol in patients with advanced gastric carcinoma. Cancer J Sci Am 4: 269-274, 1998.

3. Einzig AI, Neuberg D, Remick SC, Karp DD, O'Dwyer PJ Stewart JA and Benson AB III: Phase II trial of docetaxel (Taxotere) in patients with adenocarcinoma of the upper gastrointestinal tract previously untreated with cytotoxic chemotherapy: The Eastern Cooperative Oncology Group (ECOG) results of protocol E1293. Med Oncol 13: 87-93, 1996.

4. Futatsuki K, Wakui A, Nakao I, Sakata Y, Kambe M, Shimada Y, Yoshino M, Taguchi T and Ogawa N: Late phase II study of irinotecan hydrochloride (CPT-11) in advanced gastric cancer. CPT-11 Gastrointestinal Cancer Study Group. Gan To Kagaku Ryoho 21: 1033-1038, 1994 (In Japanese).

5. Sakata Y, Ohtsu A, Horikoshi N, Sugimachi K, Mitachi Y and Taguchi T: Late phase II study of novel oral fluoropyrimidine anticancer drug S-1 (1 M tegafur- $0.4 \mathrm{M}$ gimestat-1 M otastat potassium) in advanced gastric cancer patients. Eur J Cancer 34: 1715-1720, 1998.

6. Taguchi T, Tsukagoshi S, Furue H, Niitani H and Noda K: Phase I clinical study of oxaliplatin. Gan To Kagaku Ryoho 25: 1899-1907, 1998 (In Japanese).

7. Liu C, Sun Q, Hang X, Zhong B and Wang D: Multicenter phase II study of capecitabine plus oxaliplatin as a first-line therapy in Chinese patients with advanced gastric cancer. Anticancer Drugs 19: 825-831, 2008.
8. Koizumi W, Narahara H, Hara T, Takagane A, Akiya T, Takagi M, Miyashita K, Nishizaki T, Kobayashi O, Takiyama W, et al: S-1 plus cisplatin versus $\mathrm{S}-1$ alone for first-line treatment of advanced gastric cancer (SPIRITS trial): A phase III trial. Lancet Oncol 9: 215-221, 2008

9. Japanese Gastric Cancer Association: Japanese classification of gastric carcinoma: 3rd English edition. Gastric Cancer 14: 101-112, 2011.

10. Bang YJ, Van Cutsem E, Feyereislova A, Chung HC, Shen L, Sawaki A, Lordick F, Ohtsu A, Omuro Y, Satoh T, et al: ToGA Trial Investigators: Trastuzumab in combination with chemotherapy versus chemotherapy alone for treatment of HER2-positive advanced gastric or gastro-oesophageal junction cancer (ToGA): A phase 3, open-label, randomized controlled trial. Lancet 376: 687-697, 2010.

11. Wilke H, Muro K, Van Cutsem E, Oh SC, Bodoky G, Shimada Y, Hironaka S, Sugimoto N, Lipatov O, Kim TY, et al; RAINBOW Study Group: Ramucirumab plus paclitaxel versus placebo plus paclitaxel in patients with previously treated advanced gastric or gastro-oesophageal junction adenocarcinoma (RAINBOW): A double-blind, randomised phase 3 trial. Lancet Oncol 15: 1224-1235, 2014.

12. Boon T, De Plaen E, Lurquin C, Van den Eynde B, van der Bruggen P, Traversari C, Amar-Costesec A and Van Pel A: Identification of tumour rejection antigens recognized by $\mathrm{T}$ lymphocytes. Cancer Surv 13: 23-37, 1992.

13. Rosenberg SA, Yang JC and Restifo NP: Cancer immunotherapy: Moving beyond current vaccines. Nat Med 10: 909-915, 2004.

14. Kantoff PW, Higano CS, Shore ND, Berger ER, Small EJ, Penson DF, Redfern CH, Ferrari AC, Dreicer R, Sims RB, et al; IMPACT Study Investigators: Sipuleucel-T immunotherapy for castration-resistant prostate cancer. N Engl J Med 363: 411-422, 2010.

15. Schwartzentruber DJ, Lawson DH, Richards JM, Conry RM, Miller DM, Treisman J, Gailani F, Riley L, Conlon K, Pockaj B, et al: gp100 peptide vaccine and interleukin-2 in patients with advanced melanoma. N Engl J Med 364: 2119-2127, 2011.

16. Weber JS, O'Day S, Urba W, Powderly J, Nichol G, Yellin M, Snively J and Hersh E: Phase I/II study of ipilimumab for patients with metastatic melanoma. J Clin Oncol 26: 5950-5956, 2008.

17. Teh MT, Wong ST, Neill GW, Ghali LR, Philpott MP and Quinn AG: FOXM1 is a downstream target of Gli1 in basal cell carcinomas. Cancer Res 62: 4773-4780, 2002.

18. Wierstra I and Alves J: FOXM1, a typical proliferation-associated transcription factor. Biol Chem 388: 1257-1274, 2007.

19. Wang IC, Chen YJ, Hughes D, Petrovic V, Major ML, Park HJ, Tan Y, Ackerson T and Costa RH: Forkhead box M1 regulates the transcriptional network of genes essential for mitotic progression and genes encoding the SCF (Skp2-Cks1) ubiquitin ligase. Mol Cell Biol 25: 10875-10894, 2005.

20. Laoukili J, Kooistra MR, Brás A, Kauw J, Kerkhoven RM, Morrison A, Clevers H and Medema RH: FoxM1 is required for execution of the mitotic programme and chromosome stability. Nat Cell Biol 7: 126-136, 2005.

21. Kalinichenko VV, Major ML, Wang X, Petrovic V, Kuechle J, Yoder HM, Dennewitz MB, Shin B, Datta A, Raychaudhuri P, et al: Foxm1b transcription factor is essential for development of hepatocellular carcinomas and is negatively regulated by the p19ARF tumor suppressor. Genes Dev 18: 830-850, 2004.

22. Wonsey DR and Follettie MT: Loss of the forkhead transcription factor FoxM1 causes centrosome amplification and mitotic catastrophe. Cancer Res 65: 5181-5189, 2005.

23. Kalin TV, Wang IC, Ackerson TJ, Major ML, Detrisac CJ, Kalinichenko VV, Lyubimov A and Costa RH: Increased levels of the FoxM1 transcription factor accelerate development and progression of prostate carcinomas in both TRAMP and LADY transgenic mice. Cancer Res 66: 1712-1720, 2006.

24. Liu M, Dai B, Kang SH, Ban K, Huang FJ, Lang FF, Aldape KD, Xie TX, Pelloski CE, Xie K, et al: FoxM1B is overexpressed in human glioblastomas and critically regulates the tumorigenicity of glioma cells. Cancer Res 66: 3593-3602, 2006.

25. Chan DW, Yu SY, Chiu PM, Yao KM, Liu VW, Cheung AN and Ngan HY: Overexpression of FOXM1 transcription factor is associated with cervical cancer progression and pathogenesis. J Pathol 215: 245-252, 2008.

26. Uddin S, Ahmed M, Hussain A, Abubaker J, Al-Sanea N, AbdulJabbar A, Ashari LH, Alhomoud S, Al-Dayel F, Jehan Z, et al: Genome-wide expression analysis of Middle Eastern colorectal cancer reveals FOXM1 as a novel target for cancer therapy. Am J Pathol 178: 537-547, 2011 
27. Kim IM, Ackerson T, Ramakrishna S, Tretiakova M, Wang IC, Kalin TV, Major ML, Gusarova GA, Yoder HM, Costa RH, et al: The Forkhead Box m1 transcription factor stimulates the proliferation of tumor cells during development of lung cancer. Cancer Res 66: 2153-2161, 2006.

28. Okada K, Fujiwara Y, Takahashi T, Nakamura Y, Takiguchi S, Nakajima K, Miyata H, Yamasaki M, Kurokawa Y, Mori M, et al: Overexpression of forkhead box M1 transcription factor (FOXM1) is a potential prognostic marker and enhances chemoresistance for docetaxel in gastric cancer. Ann Surg Oncol 20: 1035-1043, 2013

29. Higashihara Y, Kato J, Nagahara A, Izumi K, Konishi M, Kodani T, Serizawa N, Osada T and Watanabe S: Phase I clinical trial of peptide vaccination with URLC10 and VEGFR1 epitope peptides in patients with advanced gastric cancer. Int J Oncol 44 662-668, 2014.

30. Murahashi M, Hijikata Y, Yamada K, Tanaka Y, Kishimoto J, Inoue $\mathrm{H}$, Marumoto $\mathrm{T}$, Takahashi A, Okazaki $\mathrm{T}$ and Takeda $\mathrm{K}$ : Phase I clinical trial of a five-peptide cancer vaccine combined with cyclophosphamide in advanced solid tumors. Clin Immunol 166-167: 48-58, 2016

31. Suzuki N, Hazama S, Ueno T, Matsui H, Shindo Y, Iida M, Yoshimura K, Yoshino S, Takeda K and Oka M: A phase I clinical trial of vaccination with KIF20A-derived peptide in combination with gemcitabine for patients with advanced pancreatic cancer. J Immunother 37: 36-42, 2014

32. Yoshimura K, Minami T, Nozawa M and Uemura H: Phase I clinical trial of human vascular endothelial growth factor receptor 1 peptide vaccines for patients with metastatic renal cell carcinoma. Br J Cancer 108: 1260-1266, 2013.

33. Therasse P, Arbuck SG, Eisenhauer EA, Wanders J, Kaplan RS, Rubinstein L, Verweij J, Van Glabbeke M, van Oosterom AT, Christian MC, et al: New guidelines to evaluate the response to treatment in solid tumors. European Organization for Research and Treatment of Cancer, National Cancer Institute of the United States, National Cancer Institute of Canada. J Natl Cancer Inst 92: 205-216, 2000.
34. Iinuma H, Fukushima R, Inaba T, Tamura J, Inoue T, Ogawa E, Horikawa M, Ikeda Y, Matsutani N, Takeda K, et al: Phase I clinical study of multiple epitope peptide vaccine combined with chemoradiation therapy in esophageal cancer patients. J Trans Med 12: 84, 2014.

35. Obara W, Ohsawa R, Kanehira M, Takata R, Tsunoda T, Yoshida K, Takeda K, Katagiri T, Nakamura Y and Fujioka T: Cancer peptide vaccine therapy developed from oncoantigens identified through genome-wide expression profile analysis for bladder cancer. Jpn J Clin Oncol 42: 591-600, 2012.

36. Asahara S, Takeda K, Yamao K, Maguchi $\mathrm{H}$ and Yamaue $\mathrm{H}$ : Phase I/II clinical trial using HLA-A24-restricted peptide vaccine derived from KIF20A for patients with advanced pancreatic cancer. J Transl Med 11: 291, 2013.

37. Masuzawa T, Fujiwara Y, Okada K, Nakamura A, Takiguchi S, Nakajima K, Miyata H, Yamasaki M, Kurokawa Y, Osawa R, et al: Phase I/II study of S-1 plus cisplatin combined with peptide vaccines for human vascular endothelial growth factor receptor 1 and 2 in patients with advanced gastric cancer. Int $\mathbf{J}$ Oncol 41: $1297-1304,2012$.

38. Kono K, Iinuma H, Akutsu Y, Tanaka H, Hayashi N, Uchikado Y, Noguchi T, Fujii H, Okinaka K, Fukushima R, et al: Multicenter, phase II clinical trial of cancer vaccination for advanced esophageal cancer with three peptides derived from novel cancer-testis antigens. J Transl Med 10: 141, 2012.

39. Finn OJ, Khleif SN and Herberman RB: The FDA guidance on therapeutic cancer vaccines: The need for revision to include preventive cancer vaccines or for a new guidance dedicated to them. Cancer Prev Res (Phila) 8: 1011-1016, 2015. 